\title{
BMJ Open Waist circumference values equivalent to body mass index points for predicting absolute cardiovascular disease risks among adults in an Aboriginal community: a prospective cohort study
}

\author{
Odewumi Adegbija, Wendy E Hoy, Zhiqiang Wang
}

To cite: Adegbija 0, Hoy WE, Wang Z. Waist circumference values equivalent to body mass index points for predicting absolute cardiovascular disease risks among adults in an Aboriginal community: a prospective cohort study. BMJ Open 2015;5:e009185. doi:10.1136/bmjopen-2015009185

- Prepublication history for this paper is available online. To view these files please visit the journal online (http://dx.doi.org/10.1136/ bmjopen-2015-009185).

Received 25 June 2015 Revised 22 October 2015 Accepted 23 October 2015

CrossMark

Centre for Chronic Disease, School of Medicine, University of Queensland, Brisbane, Queensland, Australia

Correspondence to Odewumi Adegbija; o.adegbija@uq.edu.au

\section{ABSTRACT}

Objective: There have been suggestions that currently recommended waist circumference (WC) cut-off points for Australians of European origin may not be applicable to Aboriginal people who have different body habitus profiles. We aimed to generate equivalent WC values that correspond to body mass index (BMI) points for identifying absolute cardiovascular disease (CVD) risks.

Design: Prospective cohort study.

Setting: An Aboriginal community in Australia's Northern Territory.

Participants: From 1992 to 1998, 920 adults without CVD, with age, WC and BMI measurements were followed-up for up to 20 years.

Outcome measures: Incident CVD, coronary artery disease (CAD) and heart failure (HF) events during the follow-up period ascertained from hospitalisation data. We generated WC values with 10-year absolute risks equivalent for the development of CVD as BMI values (20-34 kg/m²) using the Weibull accelerated timefailure model.

Results: There were 211 incident cases of CVD over 13669 person-years of follow-up. At the average age of 35 years, WC values with absolute CVD, CAD and HF risks equivalent to BMI of $25 \mathrm{~kg} / \mathrm{m}^{2}$ were $91.5,91.8$ and $91.7 \mathrm{~cm}$, respectively, for males, and corresponding WC values were $92.5,92.7$ and $93 \mathrm{~cm}$ for females. WC values with equal absolute CVD, CAD and $\mathrm{HF}$ risks to $\mathrm{BMI}$ of $30 \mathrm{~kg} / \mathrm{m}^{2}$ were $101.7,103.1$ and $102.6 \mathrm{~cm}$, respectively, for males, and corresponding values were 99.2, 101.6 and $101.5 \mathrm{~cm}$ for females. Association between WC and CVD did not depend on gender $(p=0.54)$.

Conclusions: WC ranging from 91 to $93 \mathrm{~cm}$ was equivalent to BMI $25 \mathrm{~kg} / \mathrm{m}^{2}$ for overweight, and 99 to $103 \mathrm{~cm}$ was equivalent to $\mathrm{BMI}$ of $30 \mathrm{~kg} / \mathrm{m}^{2}$ for obesity in terms of predicting 10-year absolute CVD risk. Replicating the absolute risk method in other Aboriginal communities will further validate the WC values generated for future development of WC cut-off points for Aboriginal people.

\section{Strengths and limitations of this study}

- This study presented waist circumference (WC) values that correspond to equivalent body mass index (BMI) points for cardiovascular disease (CVD) risk in an Aboriginal population in Australia.

- The use of prospective cohort study and the long-term follow-up (up to 20 years) enabled calculating absolute risk based on future CVD events which provided proof of the WC values generated from BMI points.

- Third, the data on which our results are based were derived from an Aboriginal community and are likely specific to this Northern Territory community.

- Although results might not be generalisable to other Aboriginal communities, it is a representative sample of a homogeneous Aboriginal population.

- While over $80 \%$ of community members were participants of this study, the sample size was still limited and it will be helpful if further studies are conducted in larger Aboriginal settings to validate the findings of the present study.

- The use of hospitalisation data alone would not have captured all incident CVD cases in the study population. Future studies employing the use of primary healthcare and private health systems will identify more CVD events.

\section{INTRODUCTION}

The importance of waist circumference (WC) in health assessment in relation to chronic diseases such as cardiovascular disease (CVD) prevention is well recognised in current guidelines and policies in Australia. These guidelines include the 'National guide to a preventive health evaluation in Aboriginal and Torres Strait Islander peoples' by National Aboriginal Community 
Controlled Health Organisation (NACCHO), and the 'Clinical Practice Guidelines for the Management of Overweight and Obesity in Adults' by the National Health and Medical Research Council. The Central Australian Rural Practitioners Association (CARPA) Standard Treatment Manual recommends WC measures be included in all yearly Adult Health Checks. ${ }^{1}$ Although this is a major achievement in creating awareness of the importance of WC, which is often not the foremost focus of most studies assessing anthropometric indices, the previously mentioned guidelines have been unable to recommend WC cut-off points for Aboriginal people who have higher CVD risk ${ }^{2}$ and have elevated $\mathrm{WC}^{3}$ compared with non-Aboriginals in Australia. Recently, the Australian, States and Territories Government sponsored the Measure-Up Campaign targeted at measuring $\mathrm{WC}$ in an effort to reduce chronic disease risk for Australians by recommending WC cut-off levels of 94 and $102 \mathrm{~cm}$ for men and 80 and $88 \mathrm{~cm}$ for women derived from body mass index (BMI) of 25 and $30 \mathrm{~kg} / \mathrm{m}^{2}$, respectively. Despite their efforts in presenting these WC cut-offs in multilingual booklets for various ethnic Australian groups, the recommended thresholds were particularly relevant to populations of European origin and might not reflect the true health risk in Aboriginal people who differ in body composition from other Australians. ${ }^{3-5}$

CVD has been reported as the leading cause of death among Aboriginal people who are 1.3 times as likely to develop the disease as other Australians. ${ }^{2}$ Elevated WC has been known to increase the risk of any CVD,${ }^{6-8}$ coronary artery disease $(\mathrm{CAD})^{9}$ and heart failure $(\mathrm{HF}) .^{10}{ }^{11}$ Aboriginal people, particularly females, have body composition characterised by relatively higher WC compared with non-Aboriginals, which has been associated with increased risk of CVD. ${ }^{6-8}$ Although WC has been reported to have stronger association with CVD than BMI in Aboriginal communities, ${ }^{6}$ both WC and BMI are useful predictors of CVD. ${ }^{9}{ }^{12}$ Using a longitudinal follow-up study design, we aimed to evaluate WC values corresponding to BMI points with equal absolute CVD, CAD and $\mathrm{HF}$ risks in an Aboriginal community in Australia. The WC values generated will assist future research by contributing to the needed evidence for the recommendation of WC cut-off points applicable to the Aboriginal population.

\section{METHODS}

\section{Study setting and participants}

The study was a prospective cohort study which included two phases: the baseline and follow-up. At a baseline community screening programme conducted from 1992 to 1998 in a remote Aboriginal community in the Northern Territory of Australia, age as well as anthropometric indices such as WC, weight, height and BMI were recorded, details have been discussed elsewhere. ${ }^{6}$

A total of 976 adults (aged 18 years and above) participated in the baseline screening programme of whom
934 had records of age (years), as well as WC and BMI measurements. Out of the 934 adults, 920 were free from known CVD at baseline and were eligible for the present study. They represented over $90 \%$ of adults in the study sample. These 920 adults (468 males and 452 females) were included in the study and prospectively followed up for up to 20 years (until 31 May 2012) to identify hospital-diagnosed new incident cases of CVD through hospitalisation data obtained from public hospitals in the Northern Territory.

\section{Anthropometric measurements}

Baseline WC in centimetres was measured midway between the lower border of the ribs and the iliac crest. Baseline BMI was calculated as baseline weight (kilograms) divided by the square of baseline height (metres).

\section{Outcomes measurements}

The hospitalisation database included hospital and emergency admission records of individuals in the Northern Territory. The CVD cases during the follow-up period were determined from the hospitalisation records using the following International Classification of Diseases (ICD) codes: 402-404, 410-458 (ICD-9) and I11-I13, I20-I28, I50, I60-I89 (ICD-10) for CVD; 402-404, 410-417, 427.5, 428, 430-459 (ICD-9) and I20 to I25 (ICD-10) for CAD; and 428 (ICD-9) and I50 (ICD-10) for HF. For the purpose of this study, we excluded rheumatic fever and diseases as well as hypotension, haemorrhoids and other CVDs, that WC has not been found to have a causal relationship. On the other hand, we included hypertensive heart disease and hypertensive renal disease due to their associations with the complications of high blood pressure to which $\mathrm{BMI}^{13}{ }^{14}$ and elevated $\mathrm{WC}^{15}{ }^{16}$ have been documented as risk factors. Death records were checked for CVD cases that were not recorded in the hospital data. The follow-up time for each participant was calculated from baseline screening to date of disease diagnosis according to the hospital record, or date of death, or end of follow-up, whichever occurred first. Over $82 \%$ of the study participants were hospitalised for any ailment during the follow-up period as evidenced by hospitalisation records; therefore, we are positive of a robust follow-up ascertainment.

\section{Ethics statement}

The protocol of the baseline screening programme was approved by the Ethics Committee of the Menzies School of Health Research and Territory Health Service, and the Aboriginal community. All participants gave informed consent to participate.

\section{Statistical analysis}

Data were analysed separately for males and females. Mean and SD for continuous variables or frequency and percentages for categorical variables were calculated. The Weibull accelerated failure-time model was used to estimate the absolute CVD risk using the formula: 
Table 1 Characteristics of participants

\begin{tabular}{lccc}
\hline & Males $(\mathbf{n = 4 6 8 )}$ & Females $(\mathbf{n = 4 5 2 )}$ & Total $(\mathbf{n = 9 2 0 )}$ \\
\hline Age, years-mean (SD) & $33.5(11.5)$ & $36.2(13.0)$ & $35.0(12.3)$ \\
WC, $\mathrm{cm}$-mean (SD) & $87.3(13.1)$ & $90.6(14.5)$ & $88.9(13.9)$ \\
BMI, kg/m²-mean (SD) & $23.5(4.6)$ & $24.5(5.9)$ & $24.0(5.3)$ \\
& & & \\
Any CVD outcome, $\mathrm{n}(\%)$ & $104(22.2)$ & $107(23.7)$ & $211(22.9)$ \\
CAD, $\mathrm{n}(\%)$ & $69(14.7)$ & $71(15.7)$ & $140(15.1)$ \\
HF, $\mathrm{n}(\%)$ & $35(7.5)$ & $46(10.2)$ & $81(8.7)$ \\
\hline BMl, body mass index; CAD, coronary artery disease; CVD, cardiovascular disease; HF, heart failure; WC, waist circumference.
\end{tabular}

$$
\text { Absolute risk }=1-\exp \left[-\left\{\exp \left(-\beta_{0}-\mathrm{X}_{\mathrm{j}} \beta_{\mathrm{j}}\right) \mathrm{t}_{\mathrm{j}}\right\}^{\mathrm{P}}\right]
$$

were $\beta_{0}$ represented the baseline BMI or WC coefficient, $\beta_{\mathrm{j}}$ was the coefficient for covariates (BMI or WC and age), $X_{j}$ represented the covariates, $t=$ time and $p=$ shape parameter.

The absolute risk method was employed to obtain estimates of equivalent WC values that corresponded to BMI values from 20 to $34 \mathrm{~kg} / \mathrm{m}^{2}$ for a 10 -year CVD risk in males and females at the average age of 35 years. Interaction was tested for gender in relation to $\mathrm{WC}$ and risk of CVD using fractional polynomial regression. In addition, we independently assessed $\mathrm{CAD}$ and $\mathrm{HF}$ to obtain WC points from BMI with equivalent absolute risks. Statistical analyses were performed with STATA statistical software V.13.0. ${ }^{17}$ The tests were two-tailed and we used $p<0.05$ as the level of statistical significance.

\section{RESULTS}

\section{Characteristics of the participants}

The study sample comprised 920 participants, including $452(49 \%)$ females. Compared with males, the average age, WC and BMI were higher in females. Table 1 shows the baseline characteristics of the study participants. During an average follow-up time of 14.8 years, a total of 211 participants developed CVD. A total of 140 CAD and $81 \mathrm{HF}$ incident cases were recorded. In general, a greater proportion of females than males had CVD (23.7-22.2\%), CAD (15.7-14.7\%) and HF (10.2-7.5\%) outcomes.

Tables 2 and 3 show the estimated 10-year absolute CVD risks according to baseline values of $20-34 \mathrm{~kg} / \mathrm{m}^{2}$ and corresponding WC values with equivalent risks, with age being fixed to 35 years, the average age of the study sample. For males, 10 years CVD absolute risk was $10.62 \%$ for BMI of $20 \mathrm{~kg} / \mathrm{m}^{2}$ compared with $21.47 \%$ for BMI of $34 \mathrm{~kg} / \mathrm{m}^{2}$. Corresponding values for WC associated with similar CVD risks in females were $11.97 \%$ and $17.46 \%$ for BMI of 20 and $34 \mathrm{~kg} / \mathrm{m}^{2}$, respectively. Similar patterns were observed for $\mathrm{CAD}$ and $\mathrm{HF}$ as shown in tables 2 and 3 . Figure 1 shows WC values corresponding to same absolute CVD risks with BMI points were similar for CVD, CAD and HF. The maximum differences for specific WC values generated ranged from -2.2 to $+4.3 \mathrm{~cm}$ for CVD, CAD and HF.

Table 2 Estimated ARs associated with CVD types using equivalent WCs corresponding to BMI values for males at the age of 35 years

\begin{tabular}{|c|c|c|c|c|c|c|}
\hline \multirow[b]{2}{*}{ BMI $\left(\mathrm{kg} / \mathrm{m}^{2}\right)$} & \multicolumn{2}{|l|}{ CVD } & \multicolumn{2}{|c|}{ Coronary artery disease } & \multicolumn{2}{|c|}{ Heart failure } \\
\hline & WC (cm) & AR (\%) & WC (cm) & AR (\%) & WC (cm) & AR (\%) \\
\hline 20 & 81.3 & 10.62 & 80.5 & 4.09 & 81.0 & 2.37 \\
\hline 21 & 83.3 & 11.18 & 82.8 & 4.43 & 83.1 & 2.52 \\
\hline 22 & 85.4 & 11.77 & 85.0 & 4.79 & 85.2 & 2.68 \\
\hline 23 & 87.4 & 12.39 & 87.3 & 5.19 & 87.5 & 2.86 \\
\hline 24 & 89.4 & 13.04 & 89.5 & 5.61 & 89.6 & 3.05 \\
\hline 25 & 91.5 & 13.72 & 91.8 & 6.07 & 91.7 & 3.24 \\
\hline 26 & 93.5 & 14.43 & 94.1 & 6.57 & 93.9 & 3.45 \\
\hline 27 & 95.6 & 15.19 & 96.3 & 7.10 & 96.1 & 3.68 \\
\hline 28 & 97.6 & 15.97 & 98.6 & 7.68 & 98.3 & 3.92 \\
\hline 29 & 99.7 & 16.79 & 100.8 & 8.29 & 100.4 & 4.17 \\
\hline 30 & 101.7 & 17.64 & 103.1 & 8.97 & 102.6 & 4.45 \\
\hline 31 & 103.8 & 18.54 & 105.4 & 9.69 & 104.7 & 4.73 \\
\hline 32 & 105.8 & 19.47 & 107.6 & 10.46 & 106.9 & 5.03 \\
\hline 33 & 107.8 & 20.45 & 109.9 & 11.29 & 109.1 & 5.36 \\
\hline 34 & 109.9 & 21.47 & 112.1 & 12.18 & 111.2 & 5.70 \\
\hline
\end{tabular}


Table 3 Estimated ARs associated with CVD types using equivalent WCs corresponding to BMI values for females at the age of 35 years

\begin{tabular}{|c|c|c|c|c|c|c|}
\hline \multirow[b]{2}{*}{ BMI $\left(\mathrm{kg} / \mathbf{m}^{2}\right)$} & \multicolumn{2}{|l|}{ CVD } & \multicolumn{2}{|c|}{ Coronary artery disease } & \multicolumn{2}{|c|}{ Heart failure } \\
\hline & WC (cm) & AR (\%) & WC (cm) & AR (\%) & WC (cm) & AR (\%) \\
\hline 20 & 85.9 & 11.97 & 83.7 & 5.74 & 84.1 & 3.11 \\
\hline 21 & 87.3 & 12.30 & 85.5 & 6.04 & 86.1 & 3.27 \\
\hline 22 & 88.6 & 12.64 & 87.3 & 6.36 & 87.8 & 3.43 \\
\hline 23 & 90.0 & 12.99 & 89.0 & 6.70 & 89.5 & 3.61 \\
\hline 24 & 91.2 & 13.35 & 90.9 & 7.05 & 91.2 & 3.79 \\
\hline 25 & 92.5 & 13.71 & 92.7 & 7.42 & 93.0 & 3.99 \\
\hline 26 & 93.9 & 14.09 & 94.4 & 7.79 & 94.6 & 4.19 \\
\hline 27 & 95.2 & 14.48 & 96.3 & 8.20 & 96.4 & 4.41 \\
\hline 28 & 96.5 & 14.87 & 98.0 & 8.62 & 98.1 & 4.64 \\
\hline 29 & 97.8 & 15.27 & 99.8 & 9.06 & 99.8 & 4.88 \\
\hline 30 & 99.2 & 15.70 & 101.6 & 9.53 & 101.5 & 5.12 \\
\hline 31 & 100.5 & 16.12 & 103.4 & 10.02 & 103.2 & 5.38 \\
\hline 32 & 101.9 & 16.55 & 105.2 & 10.54 & 104.9 & 5.66 \\
\hline 33 & 103.2 & 16.99 & 107.0 & 11.07 & 106.7 & 5.95 \\
\hline 34 & 104.5 & 17.46 & 108.8 & 11.64 & 108.4 & 6.25 \\
\hline
\end{tabular}

For the currently recommended BMI for overweight at $25 \mathrm{~kg} / \mathrm{m}^{2}$, WC values with equivalent CVD risk were $91.5 \mathrm{~cm}$ (absolute risk=13.72\%) and $92.5 \mathrm{~cm}$ (absolute risk $=13.71 \%$ ) for males and females, respectively (tables 2 and 3). For CAD, corresponding WC values to BMI of $25 \mathrm{~kg} / \mathrm{m}^{2}$ were $91.8 \mathrm{~cm}$ (absolute risk=6.07\%) and $92.7 \mathrm{~cm}$ (absolute risk=7.42\%) for males and females, respectively. For HF, WC values with equal absolute risk with BMI of $25 \mathrm{~kg} / \mathrm{m}^{2}$ were $91.7 \mathrm{~cm}$ (absolute risk $=3.24 \%$ ) for males and $93.0 \mathrm{~cm}$ (absolute risk $=3.99 \%$ ) for females.
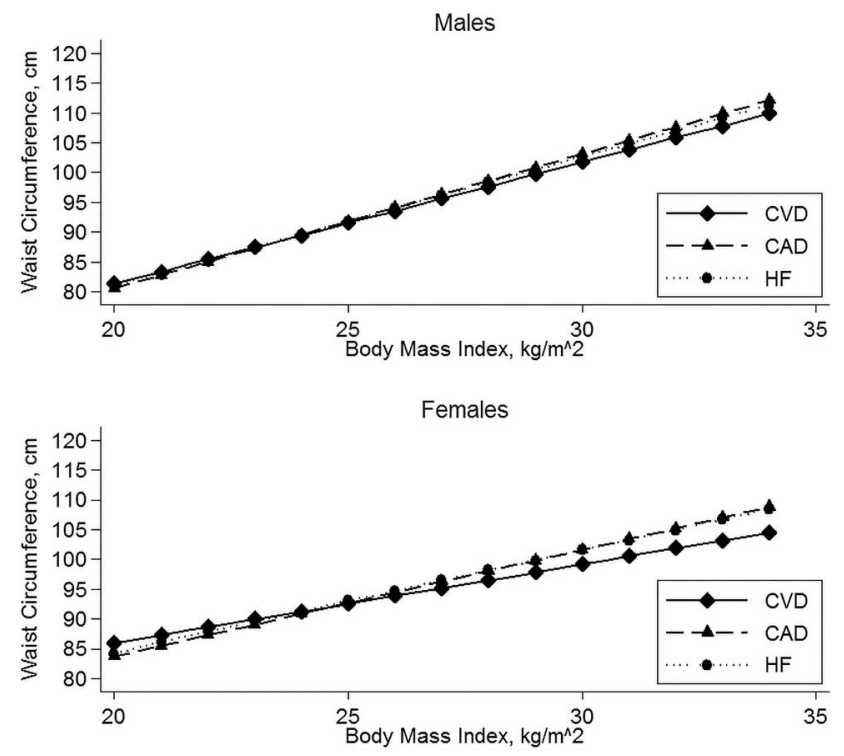

Figure 1 Estimated waist circumference with equivalent 10 -year absolute risk as body mass index for cardiovascular disease, coronary artery disease and heart failure.

CAD, coronary artery disease; CVD, cardiovascular disease; $\mathrm{HF}$, heart failure.
For the recommended BMI for obesity at $30 \mathrm{~kg} / \mathrm{m}^{2}$, WC values with the same CVD risk were $101.7 \mathrm{~cm}$ (absolute risk $=17.64 \%$ ) for males and $99.2 \mathrm{~cm}$ (absolute risk $=15.70 \%$ ) for females. For $\mathrm{CAD}$, WC values with equal risk to BMI of $30 \mathrm{~kg} / \mathrm{m}^{2}$ were $103.1 \mathrm{~cm}(8.97 \%)$ and $101.6 \mathrm{~cm}$ (absolute risk=9.53\%) for males and females, respectively. For HF, corresponding WC values to BMI of $30 \mathrm{~kg} / \mathrm{m}^{2}$ for $\mathrm{HF}$ risk were $102.6 \mathrm{~cm}$ (absolute risk $=4.45 \%$ ) and $101.5 \mathrm{~cm}$ (absolute risk $=5.12 \%$ ) for males and females, respectively.

The Weibull models below include coefficients used to estimate WC values from BMI points with equivalent absolute risks of CVD, CAD and HF.

\section{Cardiovascular diseases}

For males:

Absolute risk (BMI)

$$
\begin{aligned}
= & 1-\exp [-\{\exp (-6.3630 \\
& \left.\left.-(-0.0481 \times \mathrm{BMI}-0.0336 \times \text { Age })) \times \mathrm{t}_{\mathrm{j}}\right\}^{1.1380}\right]
\end{aligned}
$$

Absolute risk (WC)

$$
\begin{aligned}
& =1-\exp [-\{\exp (-7.1311 \\
& \left.\left.-(-0.0235 \times \mathrm{WC}-0.0287 \times \text { Age })) \times \mathrm{t}_{\mathrm{j}}\right\}^{1.1431}\right]
\end{aligned}
$$

For females:

Absolute risk (BMI)

$$
\begin{aligned}
& =1-\exp [-\{\exp (-6.5302 \\
& \left.\left.-(-0.0306 \times \mathrm{BMI}-0.0416 \times \text { Age })) \times \mathrm{t}_{\mathrm{j}}\right\}^{0.9537}\right]
\end{aligned}
$$

Absolute risk (WC)

$$
\begin{aligned}
= & 1-\exp [-\{\exp (-7.7402 \\
& \left.\left.-(-0.0230 \times \mathrm{WC}-0.0376 \times \text { Age })) \times \mathrm{t}_{\mathrm{j}}\right\}^{0.9578}\right]
\end{aligned}
$$


Coronary artery disease

For males:

Absolute risk (BMI)

$$
\begin{aligned}
= & 1-\exp [-\{\exp (-5.7600 \\
& \left.\left.-(-0.0488 \times \text { BMI }-0.0162 \times \text { Age })) \times \mathrm{t}_{\mathrm{j}}\right\}^{1.6587}\right]
\end{aligned}
$$

Absolute risk (WC)

$$
\begin{aligned}
= & 1-\exp [-\{\exp (-6.3726 \\
& \left.\left.-(-0.0216 \times \mathrm{WC}-0.0119 \times \text { Age })) \times \mathrm{t}_{\mathrm{j}}\right\}^{1.6595}\right]
\end{aligned}
$$

For females:

Absolute risk (BMI)

$$
\begin{aligned}
= & 1-\exp [-\{\exp (-7.0271 \\
& \left.\left.-(-0.0472 \times \mathrm{BMI}-0.0357 \times \text { Age })) \times \mathrm{t}_{\mathrm{j}}\right\}^{1.1168}\right]
\end{aligned}
$$

Absolute risk (WC)

$$
\begin{aligned}
= & 1-\exp [-\{\exp (-8.1433 \\
& \left.\left.-(-0.0264 \times \mathrm{WC}-0.0313 \times \text { Age })) \times \mathrm{t}_{\mathrm{j}}\right\}^{1.1159}\right]
\end{aligned}
$$

\section{Heart failure}

For males:

$$
\begin{aligned}
& \text { Absolute risk }(\mathrm{BMI}) \\
& \begin{array}{l}
=1-\exp [-\{\exp (-5.7964 \\
\left.\left.-(-0.0391 \times \mathrm{BMI}-0.0124 \times \text { Age })) \times \mathrm{t}_{\mathrm{j}}\right\}^{1.6368}\right]
\end{array}
\end{aligned}
$$

Absolute risk (WC)

$$
\begin{aligned}
= & 1-\exp [-\{\exp (-6.3449 \\
& \left.\left.-(-0.0181 \times \mathrm{WC}-0.0083 \times \text { Age })) \times \mathrm{t}_{\mathrm{j}}\right\}^{1.6333}\right]
\end{aligned}
$$

For females:

$$
\begin{aligned}
& \text { Absolute risk }(\mathrm{BMI}) \\
& \begin{array}{l}
=1-\exp [-\{\exp (-7.6541 \\
\left.\left.-(-0.0434 \times \mathrm{BMI}-0.0443 \times \text { Age })) \times \mathrm{t}_{\mathrm{j}}\right\}^{1.1788}\right]
\end{array}
\end{aligned}
$$

Absolute risk (WC)

$$
\begin{aligned}
= & 1-\exp [-\{\exp (-8.8370 \\
& \left.\left.-(-0.0255 \times \mathrm{WC}-0.0406 \times \text { Age })) \times \mathrm{t}_{\mathrm{j}}\right\}^{1.1685}\right]
\end{aligned}
$$

\section{DISCUSSION}

In our study of adults in an Aboriginal cohort, we have provided gender-specific WC values from corresponding BMI points with equivalent 10-year absolute CVD risk. WC with equivalent CVD risk as BMI of $25 \mathrm{~kg} / \mathrm{m}^{2}$ for males and females ranged from 91 to $93 \mathrm{~cm}$, and varied from 99 to $103 \mathrm{~cm}$ for BMI of $30 \mathrm{~kg} / \mathrm{m}^{2}$. There were no significant differences between males and females in their association between WC and CVD risk. When assessing absolute risks for $\mathrm{CAD}$ and $\mathrm{HF}$, we found that the absolute risk values for $\mathrm{CAD}$ and $\mathrm{HF}$ were lower than those for CVD. However, the WC values for those conditions equivalent to BMI values were not much different with a maximum difference of -2.2 to $+4.3 \mathrm{~cm}$. The absolute risks are convenient and useful for health education by health professionals and Aboriginal individuals. Furthermore, the absolute CVD risks associated with the estimated WC values in this study are useful contributions to the development of WC cut-offs for Aboriginal people in Australia.

Although Australian guidelines have made efforts to create awareness of the role of $\mathrm{WC}$ by recommending WC cut-off values as a health assessment tool to reduce the risk of chronic diseases, ${ }^{1}$ no consensus has emerged on the appropriate cut-offs for Aboriginal people, whose risk of CVD is higher than non-Aboriginals. ${ }^{18}$ Following the statement by Lear et al that the currently used WC cut-off points derived from European populations may not be appropriate for other ethnic populations, several population studies have provided evidence of WC cut-off points derived from BMI overweight and obesity thresholds to monitor the risk of developing chronic disease in adults. There have been no reports providing evidence of WC cut-off points for the Aboriginal population. The most commonly used methods for generating WC cut-off which involves optimising sensitivity and specificity whereby WC cut-off values are highly correlated with population mean values ${ }^{19}$ might not be appropriate for Aboriginal people due to substantial variations of WC mean values among different Aboriginal communities. ${ }^{3}$ There have been suggestions on applying alternative methods, such as the absolute risk method, ${ }^{19}$ particularly in heterogeneous populations as Australia. Previously, the absolute risk method has been used to assess how risk of CVD changes with different WC values. ${ }^{7}$ In the present study, the absolute risk method was employed to generate WC values from BMI with equivalent absolute CVD risk. The WC values for overweight and central obesity from BMI determined in this study will contribute to evidence required for WC cut-off if the risk is considered high enough to take actions. $^{19}$

Although there have been earlier suggestions that the appropriate BMI range for Aboriginal people is between 17 and $22 \mathrm{~kg} / \mathrm{m}^{2}$, with increased risk of metabolic conditions above $22 \mathrm{~kg} / \mathrm{m}^{2},{ }^{20}$ this is yet to be confirmed for in the population. In the present study, WC values equivalent to the risk of CVD at BMI of $22 \mathrm{~kg} / \mathrm{m}^{2}$ were about $85 \mathrm{~cm}$ for males and $87-88 \mathrm{~cm}$ for females. A proportion of $69.7 \%(69.2 \%$ in males and $70.1 \%$ in females) CVD events occurred in individuals with $\mathrm{BMI} \geq 22 \mathrm{~kg} / \mathrm{m}^{2}$ (results not presented), indicating higher CVD events among individuals with and over this BMI threshold. Owing to the heterogeneity in body composition of Aboriginal people in different communities, further research is required to confirm the healthy BMI range for CVD in the population. 
One important implication of the present study is that unique BMI and WC classifications is required for Aboriginal people as they are a diverse group with varying $\mathrm{WC}^{3}$ and $\mathrm{BMI}$ estimates across gender and regions. Variations in BMI of Aboriginal people across Australian regions have potentially been attributed to differences in socioeconomic and nutritional status. ${ }^{22} 23$ Our study results were based on gender-specific BMI and WC measures of Aboriginal people in a community in the Northern Territory. Our observations of higher BMI and WC mean estimates among females compared with males are consistent with the observations made in an earlier study involving Aboriginal people in three remote communities in the Northern Territory. ${ }^{3}$ However, results of the study from remote communities in central Australia and north Queensland showed Aboriginal males in the cohort had slightly higher WC mean estimates than females. ${ }^{8}$ The WC cut-off values from European populations for overweight $(94 \mathrm{~cm}$ in males and $80 \mathrm{~cm}$ in females) and obesity $(102 \mathrm{~cm}$ in males and $88 \mathrm{~cm}$ in females) are $14 \mathrm{~cm}$ higher for males than for females. In our calculation of the 10-year absolute risks of CVD, we found: overweight WC for BMI $\left(>=25 \mathrm{~kg} / \mathrm{m}^{2}\right)$ ranged from 91 to $93 \mathrm{~cm}$; and central obesity from BMI $\left(\geq 30 \mathrm{~kg} / \mathrm{m}^{2}\right)$ ranged from 99 to $103 \mathrm{~cm}$ for males and females. The generated WC values for these BMI thresholds were relatively similar for males and females with differences ranging from 0.9 to $2.5 \mathrm{~cm}$ for CVD, CAD and HF. This suggests that analyses using the currently proposed categories of BMI and $\mathrm{WC}$ may not identify the appropriate WC range with sufficient degree of precision.

The main strength of the present study is that it is the first to provide WC values that correspond to equivalent BMI points for CVD risk in an Aboriginal population. Our choice of WC as a measure of adiposity was based on previous findings from recent studies in the same study population suggesting WC is a better predictor of CVD compared with BMI and waist-to-hip ratio. ${ }^{7}$ Second, the prospective nature of our study enabled calculating absolute risk based on future CVD events which provided proof of the WC values generated from BMI points. ${ }^{24}$ Third, the data on which our results are based were derived from an Aboriginal community and are likely specific to this Northern Territory community. While this is advantageous due to population homogeneity, caution needs to be exercised when generalising findings to other Aboriginal communities due to heterogeneity of WC estimates in different Aboriginal communities. In addition, while over $80 \%$ of eligible community members were involved in the baseline survey, our sample size was still limited. Further work could focus on validating the WC values generated in a larger Aboriginal sample or in more Aboriginal communities. Another limitation is the use of only hospital-diagnosed CVD which may present an incomplete and potentially biased assessment of incident CVD outcomes in the community. There is a possibility that participants could have accessed care in alternative healthcare facilities instead of the public hospitals, thereby underestimating the actual CVD numbers in the study population. However, we are confident that we captured a reliable number of CVD morbidity outcome representative of the study population as over $82 \%$ of participants were hospitalised during the follow-up period evidenced by hospital records for any ailment during the follow-up period. Future studies should include records from private and primary healthcare systems for more robust CVD outcomes.

In conclusion, our study provides new and interesting observations of WC values with absolute risk of CVD equivalent to $\mathrm{BMI}$ values in an Aboriginal population. The association between WC and CVD in this study did not depend on gender. Our study suggests additional research using the absolute risk method in other Aboriginal communities will further validate the WC values generated in this study. Our findings provide valuable information to healthcare providers and evident contribution to expert committee members responsible for developing guidelines for WC cut-off points for Aboriginal people in Australia.

Acknowledgements The authors thank the Aboriginal people who participated in this study. This project was supported by National Health and Medical Research Council of Australia (APP1025350). The baseline screening was supported by NHMRC grant (320860). The authors appreciate Dr Wendy Hoy's NHMRC Australia Research Fellowship (\#511081). They thank Dr Bin Dong for his contribution towards the plotting of the graphs.

Contributors All authors contributed to the study design. WEH and ZW were involved in obtaining the original data. OA performed the literature searches, data analysis and drafted the first version of the manuscript. ZW worked closely and supervised $\mathrm{OA}$ in the data analyses. All authors revised and approved the final manuscript.

Funding This work was supported by National Health and Medical Research Council of Australia (APP1025350).

Competing interests None declared.

Ethics approval The Behavioural and Social Science Ethical Review Committee of the University of Queensland (\#2011001232).

Provenance and peer review Not commissioned; externally peer reviewed.

Data sharing statement No additional data are available.

Open Access This is an Open Access article distributed in accordance with the Creative Commons Attribution Non Commercial (CC BY-NC 4.0) license, which permits others to distribute, remix, adapt, build upon this work noncommercially, and license their derivative works on different terms, provided the original work is properly cited and the use is non-commercial. See: http:// creativecommons.org/licenses/by-nc/4.0/

\section{REFERENCES}

1. Central Australian Rural Practitioners Association (CARPA) Standard treatment manual. 5th edn. Alice Springs, 2009.

2. Australian Institute of Health and Welfare. Cardiovascular disease, diabetes and chronic kidney disease. Australian facts, Mortality, 2014. http://aihwgovau/WorkArea/DownloadAssetaspx? id $=60129549107$

3. Kondalsamy-Chennakesavan S, Hoy WE, Wang Z, et al. Anthropometric measurements of Australian Aboriginal adults living in remote areas: comparison with nationally representative findings. Am J Hum Biol 2008;20:317-24.

4. Lear SA, James PT, Ko GT, et al. Appropriateness of waist circumference and waist-to-hip ratio cutoffs for different ethnic groups. Eur J Clin Nutr 2010;64:42-61. 
5. Adegbija OO, Wang Z. Gender variations in waist circumference levels between Aboriginal and non-Aboriginal Australian populations: a systematic review. Obes Res Clin Pract 2014;8:e513-24.

6. Wang Z, Hoy WE. Waist circumference, body mass index, hip circumference and waist-to-hip ratio as predictors of cardiovascular disease in Aboriginal people. Eur J Clin Nutr 2004;58:888-93.

7. Adegbija O, Hoy W, Wang Z. Prediction of cardiovascular disease risk using waist circumference among Aboriginals in a remote Australian community. BMC Public Health 2015;15:57.

8. Piers LS, Rowley KG, Soares MJ, et al. Relation of adiposity and body fat distribution to body mass index in Australians of Aboriginal and European ancestry. Eur J Clin Nutr 2003;57:956-63.

9. Flint AJ, Rexrode KM, Hu FB, et al. Body mass index, waist circumference, and risk of coronary heart disease: a prospective study among men and women. Obes Res Clin Pract 2010;4:e171-81.

10. Hu G, Jousilahti $P$, Antikainen R, et al. Joint effects of physical activity, body mass index, waist circumference, and waist-to-hip ratio on the risk of heart failure. Circulation 2010;121:237-44.

11. Levitan EB, Yang AZ, Wolk A, et al. Adiposity and incidence of heart failure hospitalization and mortality: a population-based prospective study. Circ Heart Fail 2009;2:202-8.

12. Ho SC, Chen YM, Woo JL, et al. Association between simple anthropometric indices and cardiovascular risk factors. Int $J$ Obes Relat Metab Disord 2001;25:1689-97.

13. Tesfaye F, Nawi NG, Van Minh H, et al. Association between body mass index and blood pressure across three populations in Africa and Asia. J Hum Hypertens 2007;21:28-37.

14. Mungreiphy NK, Kapoor S, Sinha R. Association between BMI, blood pressure, and age: study among Tangkhul Naga tribal males of Northeast India. J Anthropol 2011;Article ID 748147, 6 pages.
15. Siani A, Cappuccio FP, Barba G, et al. The relationship of waist circumference to blood pressure: the Olivetti Heart Study. Am J Hypertens 2002;15:780-6.

16. Guagnano MT, Ballone E, Colagrande V, et al. Large waist circumference and risk of hypertension. Int $J$ Obes Relat Metab Disord 2001;25:1360-4.

17. StataCorp. Stata Statistical Software: Release 13. College Station, TX: StataCorp LP, 2013.

18. Australian Institute of Health and Welfare. Cardiovascular disease and its associated risk factors in Aboriginal and Torres Strait Islander peoples 2004-05 Cat no CVD 41. 2008.

19. Wang Z, Ma J, Si D. Optimal cut-off values and population means of waist circumference in different populations. Nutr Res Rev 2010;23:191-9

20. World Health Organisation. Obesity prevention and managing the global epidemic. Geneva: World Health Organisation, 1997.

21. National Health and Medical Research Council. Acting on Australia's weight: a strategic plan for the prevention of overweight and obesity. Canberra: AGPS, 1997.

22. Wang Z, Hoy W, McDonald S. Body mass index in aborigina Australians in remote communities. Aust N Z J Public Health 2000;24:570-5.

23. Cunningham J, Mackerras D. Overweight and obesity, indigenous Australians. Occasional paper-4702.0, Canberra: Australian Bureau of Statistics, 1994:20-30. http://wwwausstatsabsgovau/ausstats/ freensf/0/ECB3E89F6356B5B9CA256AD9001CFDA7/-File/ 47020pdf

24. Lean ME, Han TS, Morrison CE. Waist circumference as a measure for indicating need for weight management. BMJ 1995;311:158-61. 